\title{
Wood and Quartz Substituted Composite Material Characteristics
}

\begin{abstract}
Korkmaz Y1ldırım $^{\mathrm{a}, *}$ and Yüksel FurkanYıldırım ${ }^{\mathrm{b}}$
Many engineering designs focus on the production of durable, ergonomic, and economical new materials. In today's world where natural resources are rapidly decreasing, recycling waste materials is of great importance. As a result of the bending test, the sample's return to its original dimensions shows the plastic feature of the material. It was observed that the tensile strength can be increased if the speed of the injection machine is well adjusted in the production of tensile strength testing samples. There was an increase in the screw tensile strength of the samples and the joint hardness strength. Thermogravimetric analysis (TGA) showed that the reference samples were completely crumbled around $480^{\circ} \mathrm{C}$, and it was observed that only quartz remained from the input materials. Differential scanning calorimetry (DSC) showed that the peak point in the reference sample was at the heat flow rate of $29 \mathrm{~m} / \mathrm{W}$, while it was 18 to $19 \mathrm{~m} / \mathrm{W}$ in the doped groups. Melting temperature was observed in the range of 125 to $135^{\circ} \mathrm{C}$ in all groups. The mechanical properties of the quartz-substituted samples increased compared to the reference sample. It was observed that the quartz and wood powder contained in the mixture worked in harmony.
\end{abstract}

Keywords: Quartz; Wood powder; Composite material; Bending; Injection

Contact information: a: University of Aydin Adnan Menderes, Aydin Vocational School, Efeler, Aydin, Turkey; b: University of Beykent, Beykent Vocational School, Beylikdüzü, İstanbul, Turkey;

*Corresponding author: korkmazy54@ gmail.com

\section{INTRODUCTION}

Plastic composite products obtained from thermoplastic materials by various production methods in recent years have been used in many fields, such as the automotive industry, electronic home appliances, computer systems, white goods production, space technologies, and even artistic equipment. These materials can be formed easily; they are of low density compared to metals and their superior surface quality and resistance to corrosion have important effects on the tendency of interests towards plastic.

In a world where limited natural resources are gradually decreasing, it is important to recycle waste materials into production. Loss and waste material arise due to the unique working and production systems of each sector. Today, with the decrease of natural resources, it is of great significance to regain waste materials by using recycling systems.

A composite material contains phases that are separated from each other by their form and chemical composition and are basically insoluble in each other, such that there is a mixture or combination of two or more micro or macro components (Erol 2007). The composite material often consists of only two phases. The first phase, called the matrix, usually wraps the other phase and helps to increase the strength by providing continuity. Carbon fiber-reinforced composite materials, glass fiber-reinforced composite materials, 
car tires, plastics, ceramics, and concrete can be given as examples of composite materials. Concrete is an example of a large-particle composite known as both a matrix and ceramic.

Many engineering designs appear because of the necessity of production of new materials. Strength, ease of use, lightness, and being economical are the main objectives of the new material. The purpose of the formation of nanocomposite materials is to enable the production of new materials that work on the nano-sized molecule-based materials. When the molecular structure it contains is considered, composite materials are divided into three classes: polymeric, ceramic, and metallic. Calcium carbonate is the most commonly used filling material with polyester resin systems. In nature, it is found in the form of chalk, limestone, marble, and travertine and may contain small amounts of other minerals (Feldman 1987). In terms of weight, it is the most important filling material added to ground calcium carbonate plastics. Its finely ground variety is also used especially in polyvinyl chloride (PVC). Calcium carbonate helps both to reduce costs and to increase physical and mechanical properties (Feldman 1987).

It is thought that there are three main ways to reduce costs by adding fillers to plastics: (1) using two different materials together, (2) strengthening with fiber materials, and (3) using polymers such as polyethylene and polypropylene with minerals such as calcium carbonate (marble powder).

The cheapest and most used strategy is to create new compounds with minerals. For example, although the increase in polymer usage has slowed down in the USA, the use of minerals in the polymer industry is increasing. In Western Europe, the use of minerals in the polymer sector also rose from 278,000 tons in 1972 to 650,000 tons in 1985 , whereas the average annual polymer use increased 7\% (DPT 1996).

As previously mentioned, the use of minerals, one of the most common ways to reduce costs, naturally has brought some problems. There is a difference in surface tension between polymers that are organic materials and minerals that are inorganic. For this reason, minerals are coated to obtain better physical values. Today, over 100 known types of surface coatings are made. The surface coating commonly used in $\mathrm{CaCO}_{3}$ is made with stearic acid (DPT 1996). Nanocomposites are materials formed by the dispersion of nanometer (10 $0^{-9}$ micron)-sized particles in a matrix (Bağc1 2006). In addition to polymerbased matrices, metal and ceramic-derived materials are also used as matrices in composite materials. Although other matrices are used, $90 \%$ of composite materials are produced with polymer-based matrices (Bağc1 2006). Because the usage areas of polymers has increased by diversifying, it has become important to develop polymers that provide the mechanical, thermal, and electrical properties required by their use or to bring the existing polymers to the desired properties with additives, and studies in this direction have increased (Tavman and Turgut 2006; Swoboda et al. 2008). Due to the nanometric dimensions of the filling particles, nanocomposites have high area/volume ratios and even at low clay densities, significant increases in physical and mechanical properties can be seen because the interaction area between phases is large (Y1lmaz Bayhan 2006).

The combination of melt blending, extrusion, and compression molding methods is generally preferred by many researchers. The prerequisite for obtaining the desired polymer matrix nanocomposite sample is the regular distribution of the particles in the matrix (Tavman and Turgut 2006). Polymers' ease of processing, mechanical behavior, flexible structure, and low density are important advantages (Şahmetlioğlu et al. 2007).

In Toyota research laboratories, for the first time, clay-polymer nanocomposites combined with polymerization have shown far superior mechanical and thermal properties than organic and mineral materials (İç̧i 2007). As a result of many studies, polymeric 
nanocomposites have started to be used in automobiles today. Such materials are 10 times lighter and 10 times stronger than traditional talc filling composites in materials with low filler content. This important feature makes these materials suitable for automotive manufacturing (Y1lmaz Bayhan 2006).

Polymer composite materials are engineering products formed by connecting many monomers to each other. This new material, which is formed when the fibers of woody and annual plants and flour (powders) of woody products are combined with polymer thermoplastics, is called a wood-plastic composite. Wood fiber or dust ratio should be more than $50 \%$. The properties of wood-plastics are constituted by the used wood/fiber structure, molecular weight of thermoplastic polymer, additives, and adaptive substances (Mengeloğlu 2006).

In wood-plastic composites, the contents can include dust of wood materials or byproducts such as compacted medium-density fiberboard (MDF) or chipboard. Wood powders, such as wood flour, increase the hardness of the composite material while decreasing its durability (Jeong 2005). Thermoplastic resins (low density and high-density polyethylene and polypropylene) and wood powders are used in the production of woodplastic composite materials.

In the production of composite materials, cheapness, low density, high strength, low abrasion, and being degradable in nature provide motivations to use lignocellulosebased fibers (Chen 2009). The first wood-plastic composite was produced in 1907 by mixing wood flour and phenolics and was produced and used for commercial use as a gear lever in vehicles in 1916 . The market share, which was $2 \%$ in 1997 , increased to $18 \%$ by 2005 , and a significant increase was observed in wood-plastic composite production. There are now manufacturers of these products in many parts of the world (Balma 1999; Mengeloğlu 2006; Rowel 2006).

In this study, test samples were produced using a molding method by extruding high-density polyethylene, wood powder (flour), and quartz mineral in certain amounts as thermoplastic materials with 100 bar pressure and $45 \mathrm{~s}$ injection loading, and the produced quartz-substituted wood-plastic composite material test samples were mechanically and thermally studied with experiments. The usability of quartz as a raw material was also investigated because the waste materials must be recycled in our world where the original raw materials are being consumed rapidly.

\section{EXPERIMENTAL}

\section{Materials}

Mineral aggregate quartz.

Quartz as a filling material is preferred because it gives rigidity and high strength to the polymer concrete it is used in; this is due to its high hardness. The chemical and physical technical properties of the quartz aggregate used in the study are shown in Table 1 .

\section{Petilen YY I668 (high-density polyethylene) (HDPE)}

The PETILEN YY I668 is a product produced in accordance with the injection molding technique, with high density and narrow molecular weight distribution as per ASTM D618-96 (1998). It is an ideal material for the production of rigid and flexible products in injection molding applications. 
The injection molding method was used. Recommended processing conditions were in the range of 200 to $260{ }^{\circ} \mathrm{C}$, and the technical features of the product used are given in Table 1.

Table 1. Technical Specifications of Thermoplastic Material and Quartz Mineral

\begin{tabular}{|c|c|c|c|c|}
\hline & \multicolumn{2}{|c|}{ Petilen (HDPE) } & \multicolumn{2}{|c|}{ Quartz Mineral Properties } \\
\hline Resin Properties & $\begin{array}{l}\text { Typical } \\
\text { Value }\end{array}$ & Unit & Size of Product & 0 to 75 micron \\
\hline Melting flow rate $\left(230^{\circ} \mathrm{C}\right)$ & 5.5 & $\mathrm{~g} / 10 \mathrm{~min}$ & Hardness scale & 7 mohs \\
\hline Density & 0.965 & $\mathrm{~g} / \mathrm{cm}^{3}$ & Specific weight & $2.65 \mathrm{~g} / \mathrm{cm}^{3}$ \\
\hline $\begin{array}{l}\text { Melting point (differential } \\
\text { scanning calorimetry) }\end{array}$ & 134 & ${ }^{\circ} \mathrm{C}$ & & \\
\hline \multicolumn{2}{|l|}{ Mechanical Properties } & & \multicolumn{2}{|c|}{$\begin{array}{c}\text { Quartz Chemical Analysis } \\
\text { Report }\end{array}$} \\
\hline Tensile strength in flow & 34 & $\mathrm{MPa}$ & Compound & $\begin{array}{l}\text { Compound } \\
\text { Weight \% }\end{array}$ \\
\hline Tensile strength at break & 17 & $\mathrm{MPa}$ & $\mathrm{SiO}_{2}$ & 97.13 \\
\hline Elongation at break (MY) & 1250 & $\%$ & $\mathrm{Al}_{2} \mathrm{O}_{3}$ & 1.72 \\
\hline Flexural modulus $\left(23^{\circ} \mathrm{C}\right)$ & 1200 & $\mathrm{MPa}$ & $\mathrm{Fe}_{2} \mathrm{O}_{3}$ & 0.029 \\
\hline Izod impact resistance $\left(23^{\circ} \mathrm{C}\right)$ & 2250 & $\mathrm{~J} / \mathrm{m}$ & $\mathrm{TiO}_{2}$ & 0.031 \\
\hline Hardness (Shore-D) & 66 & R-scale & $\mathrm{CaO}$ & 0.06 \\
\hline Rockwell hardness & ---- & R-scale & $\mathrm{MgO}$ & 0.02 \\
\hline $\begin{array}{c}\text { Environmental stress fracture } \\
\text { strength }\end{array}$ & 4 & $\mathrm{~h}$ & $\mathrm{Na}_{2} \mathrm{O}$ & 0.91 \\
\hline \multicolumn{2}{|l|}{ Thermal Properties } & & $\mathrm{P}_{2} \mathrm{O}_{5}$ & 0.00 \\
\hline $\begin{array}{l}\text { Deformation temperature }(0.45 \\
\mathrm{MPa})\end{array}$ & ---- & ${ }^{\circ} \mathrm{C}$ & & \\
\hline Vicat softening point (10 N) & 124 & ${ }^{\circ} \mathrm{C}$ & & \\
\hline
\end{tabular}

Wood powder

Within the scope of the study, machine residual dust belonging to the remaining wood and wood products were used as waste material in the furniture sector. Mixing ratios of the powders were not fixed; sawdust and dust from pine, beech, poplar, MDF, chipboard, wood scraps, and some edge bands were collected. After this waste material was dried in the oven, it was ground and sieved through a sieve with a thickness of 200-mesh and a powder material was produced in the form of flour (Horta et al. 2017). When the values of the substances in this mixture were analyzed, the abundance of cellulose material were seen. The properties of the prepared wood powder (flour) are given in Table 2.

Table 2. Technical Specifications for Wood Powder (Flour)

\begin{tabular}{|c|c|c|c|c|c|}
\hline $\begin{array}{c}\text { Elemental } \\
\text { Analysis } \\
\text { Weight }\end{array}$ & $\mathrm{C} \%$ & $\mathrm{H} \%$ & $\mathrm{~N} \%$ & $\mathrm{~S} \%$ & $\mathrm{O} \%$ \\
\cline { 2 - 6 } & 50.02 & 6.62 & 1.96 & - & 47.66 \\
\hline $\begin{array}{c}\text { Analysis } \\
\text { By Weight }\end{array}$ & Volatile Matter\% & Ash\% & Moisture\% & Constant\% & $\begin{array}{c}\text { C Thermal } \\
\text { Value } \\
(\mathrm{cal} / \mathrm{g})\end{array}$ \\
\cline { 2 - 6 } & 75.68 & 1.01 & 4.10 & 19.21 & 5413.9 \\
\hline $\begin{array}{c}\text { Chemical } \\
\text { Analysis } \\
\text { Weight }\end{array}$ & \begin{tabular}{c} 
Extractable \\
\cline { 2 - 6 }
\end{tabular} & Hemicellulose\% & Cellulose\% & Lignin\% & \\
\hline
\end{tabular}




\section{Methods}

Preparation of test samples

High-density polyethylene material from thermoplastics, 200-mesh fine wood powder (flour), which is industrial waste, and quartz mineral with a fineness of less than $0.100 \mu$ (micrometers), were prepared by the method of displacement at certain rates. Denomination and mixing ratios of the experimental groups prepared for quartz, wood, and polyethylene-added composite materials are given in Table 3.

Table 3. Mixing Ratios of Experimental Sample Groups

\begin{tabular}{|l|}
\hline Reference C-0 High-density Polyethylene (100\%) \\
\hline PEWQ-1- HDPE Polyethylene(30\%) - Wood Powder(30\%)-Quartz(20\%) \\
\hline PEWQ-2- HDPE Polyethylene(50\%) - Wood Powder(20\%) - Quartz(30\%) \\
\hline PEWQ-3- HDPE Polyethylene(50\%) - Wood Powder(10\%) - Quartz(40\%) \\
\hline
\end{tabular}

The materials prepared separately with each recipe of thermoplastic, wood, and quartz materials were mixed in the mixer (KMIX200; Küçükoğlu Machine, Izmir, Turkey). All of the materials were brought together by blending them in the extruder machine (Fig. 1) $(25 / 36 \mathrm{D}$ Extruder; Sarem Machine, Izmir, Turkey)

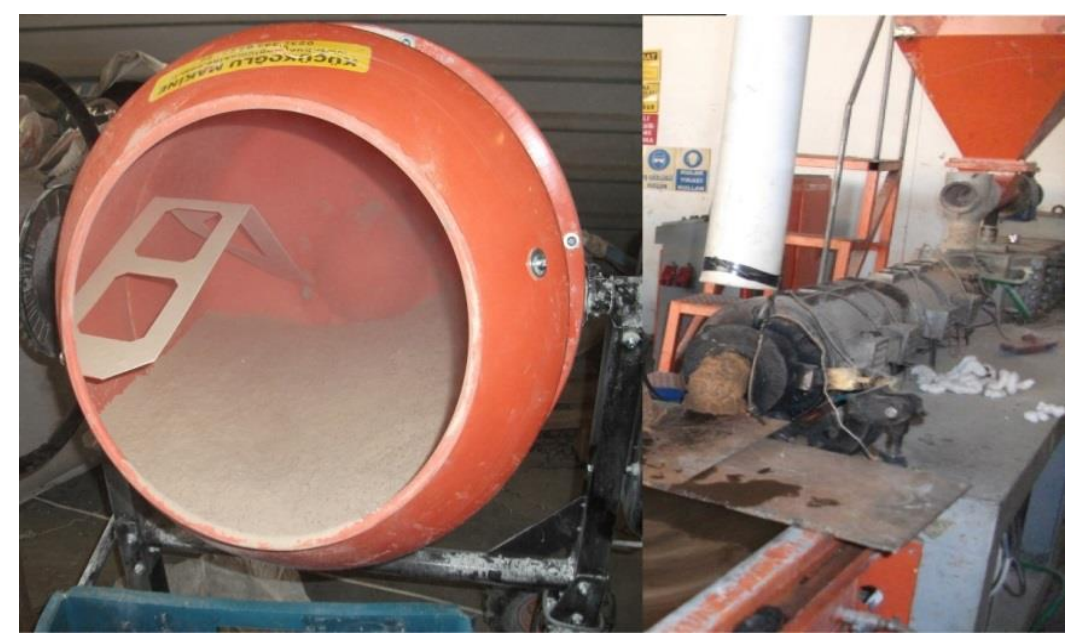

Fig. 1. Combining materials in the extruder machine

The extrusion process has played a major role in the development of the polymer processing industry. The most striking feature of the extrusion process is a cylindrical barrel and a screw rotating inside and this process is the most important polymer processing technique today. Approximately $60 \%$ of the polymers are processed by this method and become the final product (Bodur 2010). The samples that were brought together in the extruder machine were granulated in the crushing machine (Fig. 2) (SG-21EB; Hastek Machine, Aydin, Turkey).

The material, which became granular for the injection machine, was kept in the oven at a certain temperature and reduced in moisture content. To form test samples, for mechanical and thermal testing with the ready material, 100 bar pressure and $45 \mathrm{~s}$ injection loading were applied in the injection machine and the test samples were produced by molding method (Fig. 3). Four groups of material production happened under the same conditions. 


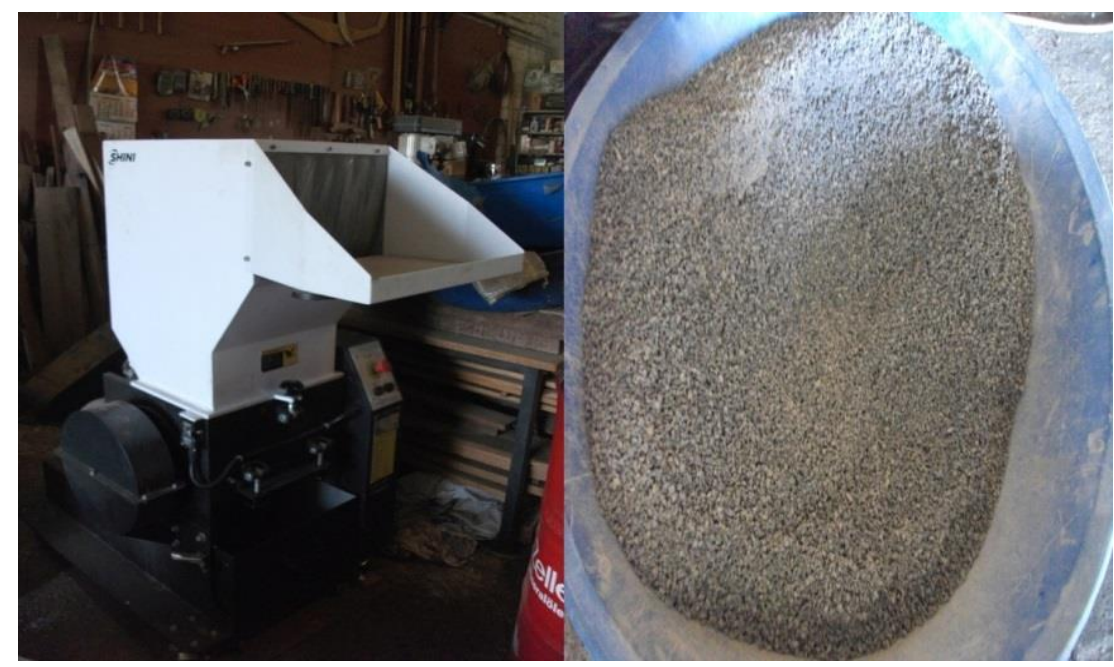

Fig. 2. Breaking the material in the crushing machine

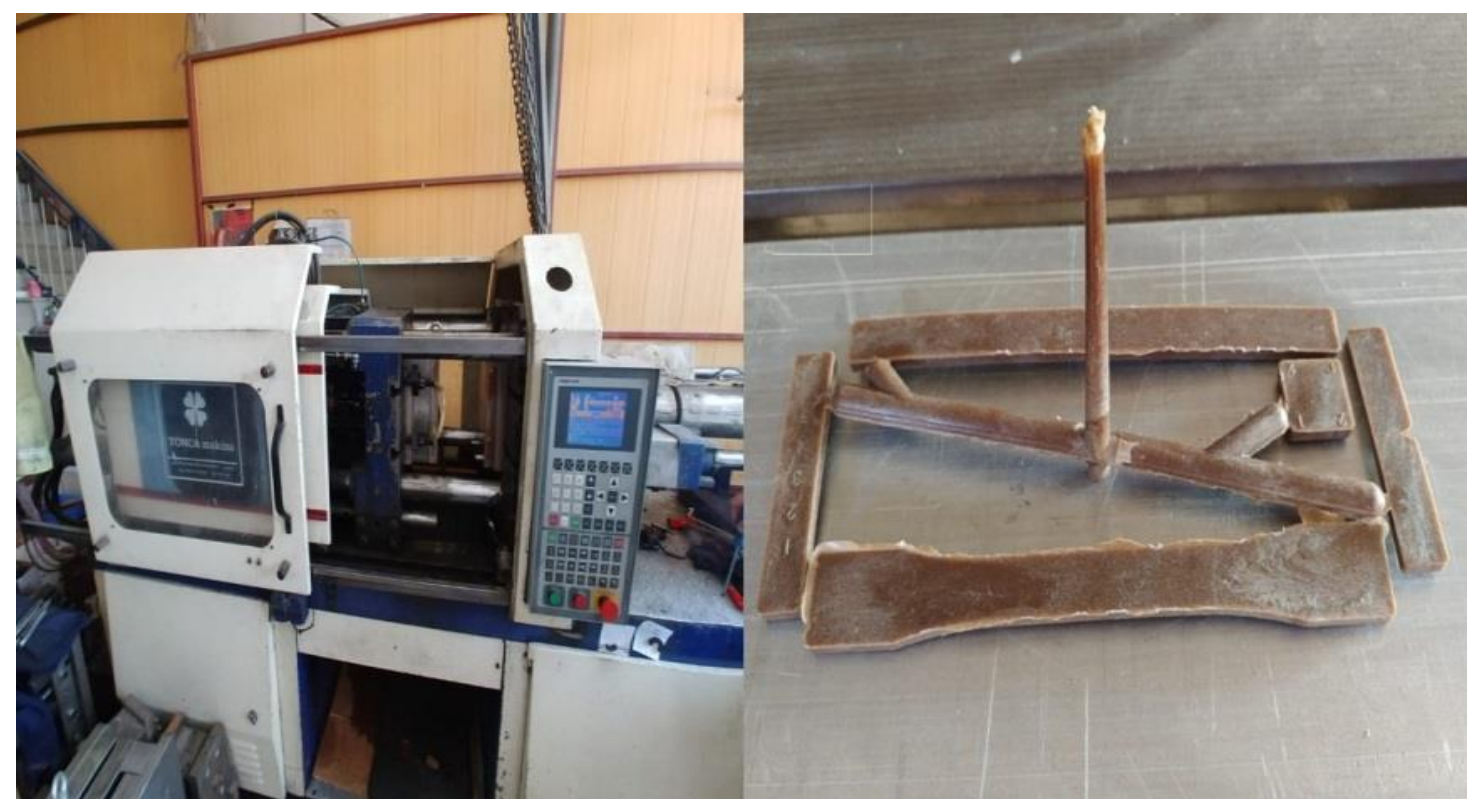

Fig. 3. Production of test samples with molding method

\section{Experimental process}

Quartz, 200-mesh fine wood flour (powder), and thermoplastic product (highdensity polyethylene) were prepared by the replacement method in certain mixtures, and with the prepared material, the extruder and test bars used in the tests after the injection processes were produced (Figs. 4 and 5). Bending, tensile strength, screw pulling, and Janka hardness tests were applied to the test samples in accordance with the standards and the results and graphics of the tests are interpreted below according to ASTM D790 (2007), ASTM D638-99 (2007), ASTM D1037 (2012), and TS EN 323 (1999).

In addition, thermogravimetric analysis (TGA) (Pyris 6 Thermogravimetric Analyzer; Perkin Elmer, Mugla, Turkey), differential scanning calorimetry (DSC) (DSC 8500 is a double-furnace DSC; PerkinElmer, Mugla, Turkey), and scanning electron microscopy (SEM) (Model; Jeol Jsm-7600f SEM; JEOL LTD., Muğla, Turkey) analyses were performed on the composite elements produced as thermal tests. 


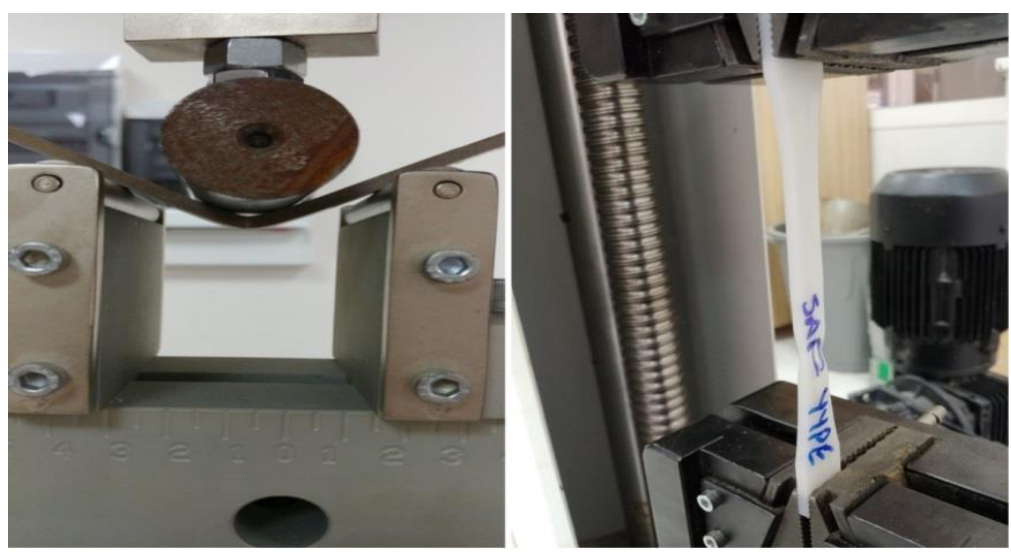

Fig. 4. Experimental process application images bending test and tensile strength test

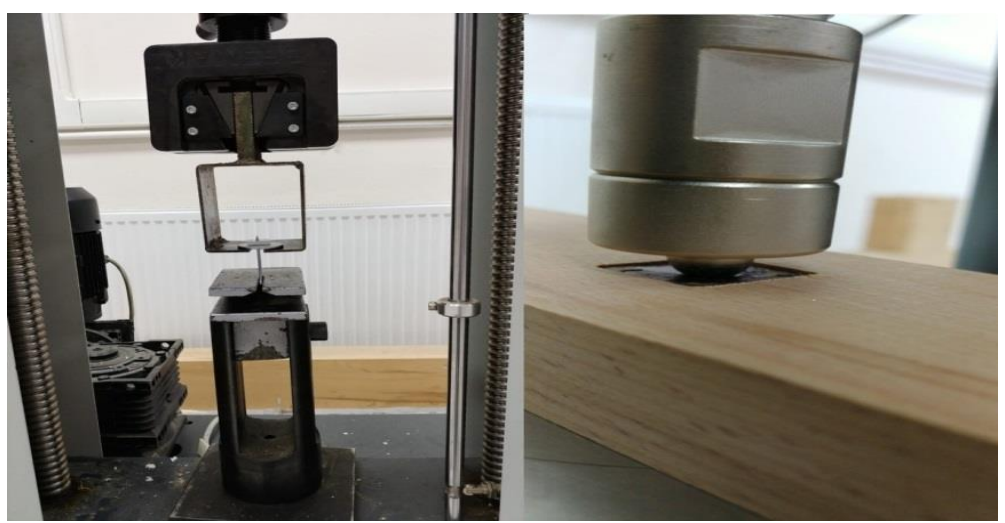

Fig. 5. Experimental process application images screw pull resistance test and Janka hardness resistance test

\section{RESULTS AND DISCUSSION}

\section{Bending Test}

It was observed that the bending resistance of the reference sample was 25.4 $\mathrm{N} / \mathrm{mm}^{2}$. In the sample PEWQ-1, there was an increase of $19.8 \%$ in the bending resistance compared to the reference sample. In the sample PEWQ-2, the bending resistance increased $3.6 \%$ compared to the PEWQ-1 group when the wood dust was less and the quartz mineral was high. In the sample PEWQ-3, the increase at the level of $3 \%$ continued in the maximum force and bending resistance compared to the group PEWQ-2 when the wood dust was low and the quartz mineral was high.

\section{Tensile Strength Test}

It was observed that the tensile strength of the reference sample was at the level of $19,700 \mathrm{~N} / \mathrm{mm}^{2}$. In the sample PEWQ-1, there was a decrease in the tensile strength compared to the reference sample, and accordingly, the tensile strength decreased at the level of $29.3 \%$. In the sample PEWQ-2, there was a decrease in the tensile strength and accordingly an increase of $3.41 \%$ compared to the group PEWQ-1. In the sample PEWQ3 , there was a slight increase in the tensile strength compared to the sample PEWQ-2 and accordingly the tensile strength increased $1.12 \%$. 


\section{Screw Pull Resistance Test}

It was observed that the threading strength obtained by the reference sample was at the level of $109.8 \mathrm{~N} / \mathrm{mm}^{2}$. In the sample PEWQ-1, there was a decrease in the threading strength compared to the reference sample, and accordingly, the threading strength was at the level of $103.0 \mathrm{~N} / \mathrm{mm}^{2}$. In the sample PEWQ-2, there was an increase in the threading strength and accordingly, the threading strength increased $2.8 \%$ compared to the group PEWQ-1. In the sample PEWQ-3, there was an increase of $0.5 \%$ in the threading resistance compared to the sample PEWQ-2 and accordingly threading strength increased proportionally with the increase of quartz.

\section{Janka Hardness Resistance Test}

It was observed that the Janka hardness value taken by the reference sample was at the level of $34.4 \mathrm{~N} / \mathrm{mm}^{2}$. In the sample PEWQ-1, there was a decrease in the tensile strength compared to the reference sample, and accordingly, the rigidity resistance of the ring was at the level of $29.4 \mathrm{~N} / \mathrm{mm}^{2}$. In the sample PEWQ-2, there was an increase in the threading strength and accordingly, the rigidity resistance value of the ring increased $4 \%$ compared to the group PEWQ-1. In the sample PEWQ-3, there was an increase of $10.3 \%$ in the hardness strength of the Janka compared to the sample PEWQ-2, and accordingly the hardness strength of the Janka increased.

Resistance values against the maximum force in the bending, tensile strength, screw pulling, and Janka hardness tests of the test bars of high-density polyethylene are shown in Table 4, and the values are plotted in Fig. 6.

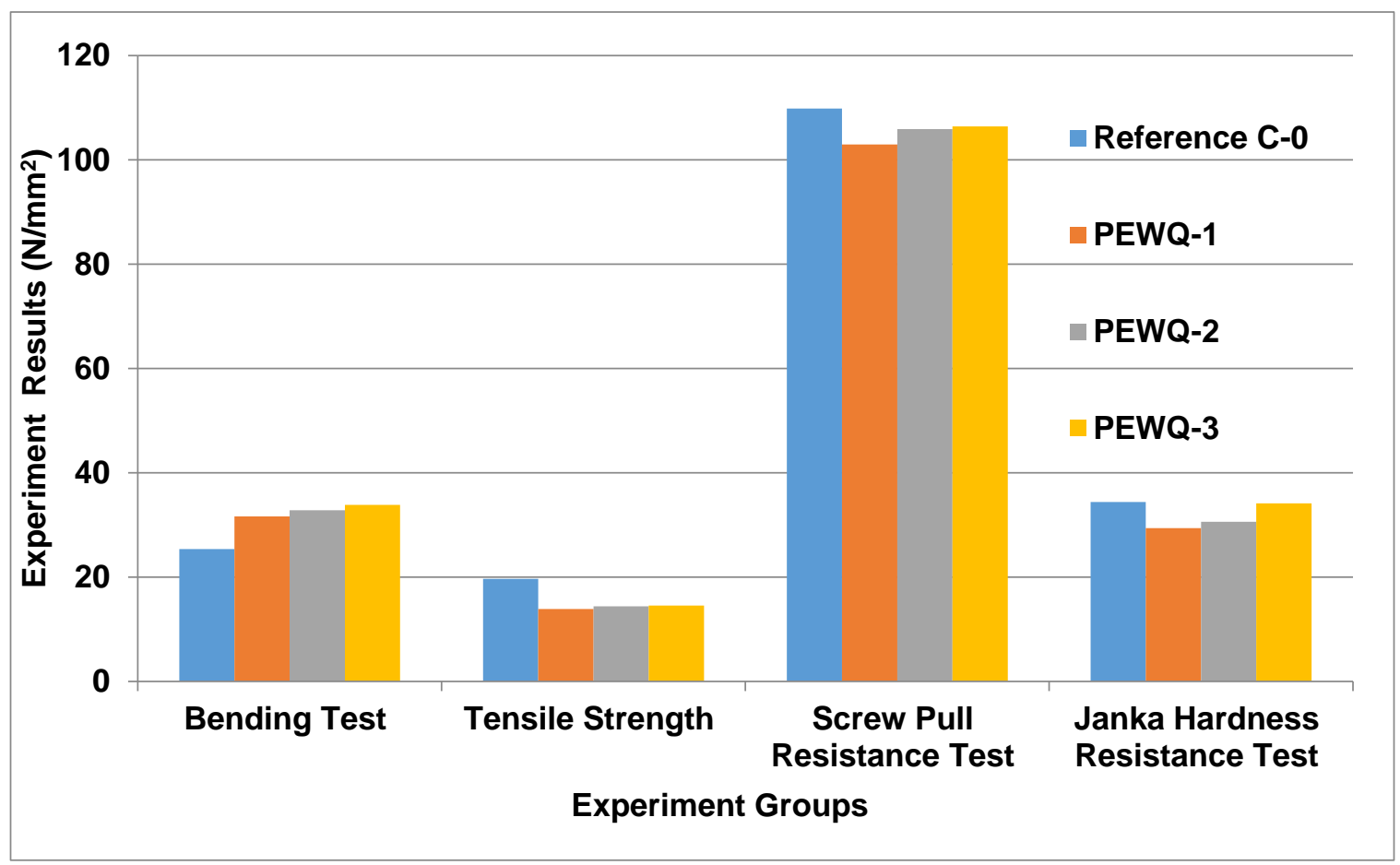

Fig. 6. The graph of bending, tensile strength, screw pulling, and Janka hardness test results on high-density polyethylene samples 
Table 4. Results of Bending, Tensile Strength, Screw Pulling, and Janka Hardness Tests on High-density Polyethylene Samples

\begin{tabular}{|c|c|c|c|c|}
\hline & $\begin{array}{c}\text { Bending Test } \\
\left(\mathrm{N} / \mathrm{mm}^{2}\right)\end{array}$ & $\begin{array}{c}\text { Tensile } \\
\text { Strength } \\
\left(\mathrm{N} / \mathrm{mm}^{2}\right)\end{array}$ & $\begin{array}{c}\text { Screw Pull } \\
\text { Resistance Test } \\
\left(\mathrm{N} / \mathrm{mm}^{2}\right)\end{array}$ & $\begin{array}{c}\text { Janka Hardness } \\
\text { Resistance Test } \\
\left(\mathrm{N} / \mathrm{mm}^{2}\right)\end{array}$ \\
\hline Reference C-0 & 25.3751 & 19.65422117 & 109.8348 & 34.38876 \\
\hline PEWQ-1 & 31.62693 & 13.89279667 & 102.9701 & 29.39389 \\
\hline PEWQ-2 & 32.82213 & 14.38313067 & 105.9121 & 30.62299 \\
\hline PEWQ-3 & 33.83346 & 14.54657533 & 106.4025 & 34.1534 \\
\hline
\end{tabular}

\section{Thermogravimetric Analysis (TGA) Results on HDPE, Wood Powder, and Quartz-substituted Composite Material}

Thermogravimetric analysis on the composite samples used in this study was recorded by selecting the nitrogen flow rate of $20 \mathrm{~mL} / \mathrm{min}$, the heating rate of $30{ }^{\circ} \mathrm{C} / \mathrm{min}$, and measuring their behavior against heating of up to $700{ }^{\circ} \mathrm{C}$.

In the study of Altuntaş et al. (2016), it was revealed that, according to the results obtained, the composite without boron $\left(288^{\circ} \mathrm{C}\right)$ lost weight earlier than the added composites $\left(308{ }^{\circ} \mathrm{C}\right)$, and moreover, when the composites added with boron compounds were compared among themselves, the disintegration of the composites with zinc boron started at $319{ }^{\circ} \mathrm{C}$ and the boron components delayed the degradation of the material according to the results of the TGA curves of the composites with boron added (Altuntaş et al. 2016).

In another study, it was understood that added boric acid and borax compounds increased the decomposition temperatures of composites (Cavdar et al. 2015).

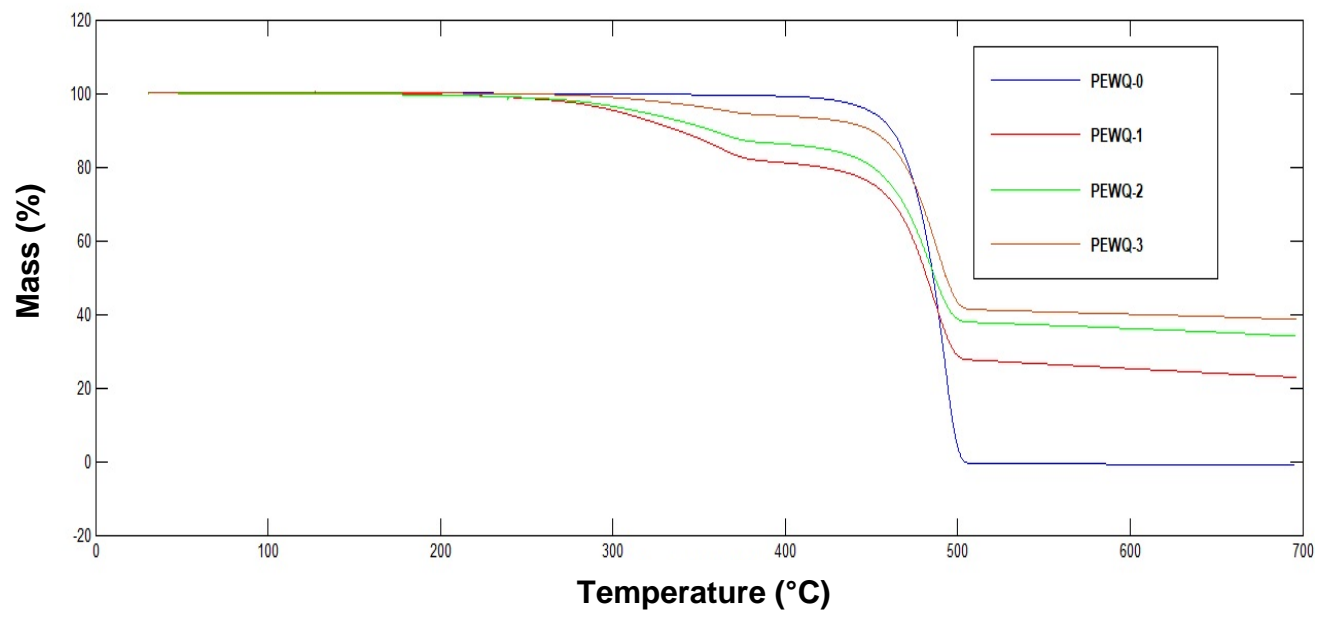

Fig. 7. TGA chart in HDPE, wood powder, and quartz-substituted composite materials

According to the results of TGA obtained, HDPE samples without additives completely dissolved around $480{ }^{\circ} \mathrm{C}$ and lost their weight. It was observed that in samples containing wood dust and quartz, the disintegration of the plastic material started after 300 ${ }^{\circ} \mathrm{C}$ and the polyethylene material and wood dust disappeared until it reached 480 to 500 ${ }^{\circ} \mathrm{C}$, but only quartz remained.

Due to the high combustion temperature of quartz, it was observed that quartz preserved its weight without deterioration after $500{ }^{\circ} \mathrm{C}$. It was understood that quartz, 
which is used as a mineral filler, retards the disintegration in the composite material and also prolongs the decomposition temperatures.

\section{Differential Scanning Calorimetry (DSC) Analysis Results on HDPE, Wood Powder, and Quartz-substituted Composite Material}

Differential scanning calorimetry is a widely used instrumental method to investigate the thermal transients of polyurethane elastomers and their layout within the sample. Therefore, DSC curves are widely used for polyurethane morphology studies (Seymour and Cooper 1974; Zielinski and Rutkowska 1986).

Differential scanning calorimetry scans of Thermoplastic Elastomers (TPEs) showed a series of typical endothermic transitions grouped into three categories. Transitions below $60{ }^{\circ} \mathrm{C}$ were associated with the glass transition temperature of the soft part, endothermic transitions between 60 and $150{ }^{\circ} \mathrm{C}$ resulted in the rearrangement of the hard/soft part interface, and transitions greater than $150{ }^{\circ} \mathrm{C}$ were due to breakage of the inner-urethane hydrogen bonds (Seymour and Cooper 1971). These transitions depend on the characteristic information of the phase morphology of the polyurethane and the thermal history of the material. Thermal annealing results in increased order in the hard area and increased phase separation within the polymer. This low soft part may be associated with endothermic assembly at higher temperatures. The transitions associated with the rearrangement of the rigid segment were sharper and indicate more annotation within the increased regular area. Differential scanning calorimetry was also used to explain the hydrogen bonding effect on polyurethane structure.

Clough and Schneider in their work on this subject studied the hydrogen bonding effect of polyether and polyester-based polyurethane using DSC, XRD, and light scattering devices (Drobny 2007). In this study, they identified two endothermic transitions, indicating two sharp types of hydrogen bonding. The transition at $80{ }^{\circ} \mathrm{C}$ was interpreted as the soft part's ether oxygen or the result of hydrogen bonds between the ester carbonyl urethane hydrogen. It is thought that the transition occurring at temperatures above $140{ }^{\circ} \mathrm{C}$ is related to internal-urethane hydrogen bonds. They asserted that the higher temperature transitions were related to the type of hydrogen bond associated with the separation of urethane groups leading to the dominant structure (Crawford 1998).

Seymour and Cooper conducted annealing studies of a series of polyether and polyester-based polyurethanes in connection with infrared spectroscopy (IR) studies. They identified many endothermic transitions related to these polymers (Seymour and Cooper 1971, 1974; Seymour et al. 1975). Seymour and Cooper named these transitions T1, T11, and T11 and observed these heat transitions as approximately $70{ }^{\circ} \mathrm{C}, 160{ }^{\circ} \mathrm{C}$, and $185{ }^{\circ} \mathrm{C}$, respectively. They attributed $\mathrm{T}_{1}$ and $\mathrm{T}_{11}$ to the degradation of the short and long range order, respectively, and clarified that the peak of T111 was associated with the melting of the microcrystalline field (Seymour and Cooper 1973; Crawford 1998).

Samples were prepared in an aluminium pan by weighing $10 \mathrm{mg}$ of polymeric materials. Starting from $-50{ }^{\circ} \mathrm{C}$, the system was heated up to $200{ }^{\circ} \mathrm{C}$ at a rate of $10{ }^{\circ} \mathrm{C} / \mathrm{min}$. The midpoint of the endothermic peak was taken as the $T_{\mathrm{g}}$ value. According to the DSC analysis chart on HDPE, wood powder, and quartz-added samples in Fig. 8, the reaction beginning temperature of the test samples started around 25 to $30{ }^{\circ} \mathrm{C}$.

The peak point of HDPE was at a heat flow rate of $29 \mathrm{~m} / \mathrm{W}$ compared to the doped ones, while it was at a heat flow rate of 18 to $19 \mathrm{~m} / \mathrm{W}$ in the groups with wood dust and quartz additives. Melting temperature was observed in the range of 125 to $135{ }^{\circ} \mathrm{C}$ in all groups.

Yıldırım \& Furkan Yıldırım (2021). "Wood-Qz composite," BioResources 16(2), 3607-3622. 3616 


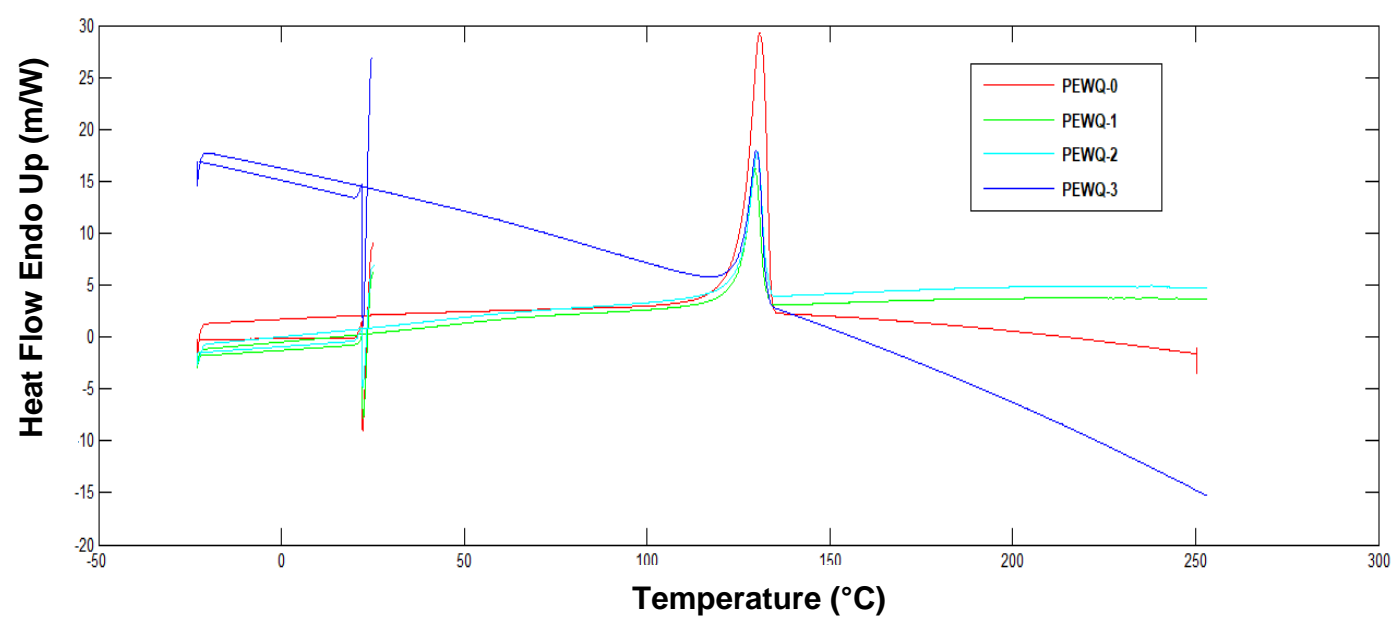

Fig. 8. DSC graph in HDPE, wood powder, and quartz-substituted composite materials

\section{Scanning Electron Microscope (SEM) Analysis of HDPE, Wood Powder, and Quartz-substituted Composite Elements}

According to scanning electron microscopy (SEM) of HDPE, wood powder, and quartz-substituted composite elements, the inorganic matter in the polymer was evenly distributed.

If the distribution of inorganic matter in the polymer matrix is uneven, the inorganic material becomes lumpy in the polymer matrix and restrains the properties of the final product from enhancing (Sormana 2005). In the SEM images (Fig. 9), the wood powder and quartz added into the test samples showed homogeneous distribution in the polymeric composite element. It was clearly seen that the components entering the mixture were compatible with the segments inside and the bonding between them.

Bending resistance, tensile, screw pulling, and joint hardness tests were performed on high-density polyethylene, wood powder, and quartz-added composite material. When the bending test started, the samples resisted up to the maximum force, and the return of the sample to its original dimensions as a result of bending showed the plastic property of the material. No break or cracks were observed in the samples thanks to the compatibility of the components in the mixture with each other.

In the samples subjected to the tensile test, it was observed that there were gaps in some parts of the test sample, which was thought to be dependent on the machine speed during injection, but the tensile strength was around $20 \mathrm{~N} / \mathrm{mm}^{2}$ in the reference sample and 13 to $14.5 \mathrm{~N} / \mathrm{mm}^{2}$ in the doped samples. It was also understood that the tensile strength could be increased by paying attention to the injection machine speed setting to prevent gaps. In the screw pull resistance test and Janka hardness resistance test results, it was observed that there was an increase in the threading resistance and Janka hardness resistance of the samples. It can be mentioned that this was due to the technical properties of HDPE and quartz. The hardness of quartz showed its effect in the experiments. As the quartz amount increased, threading and Janka hardness values increased. The adherence of the components that make up the composite material was positive in terms of mechanical properties. 

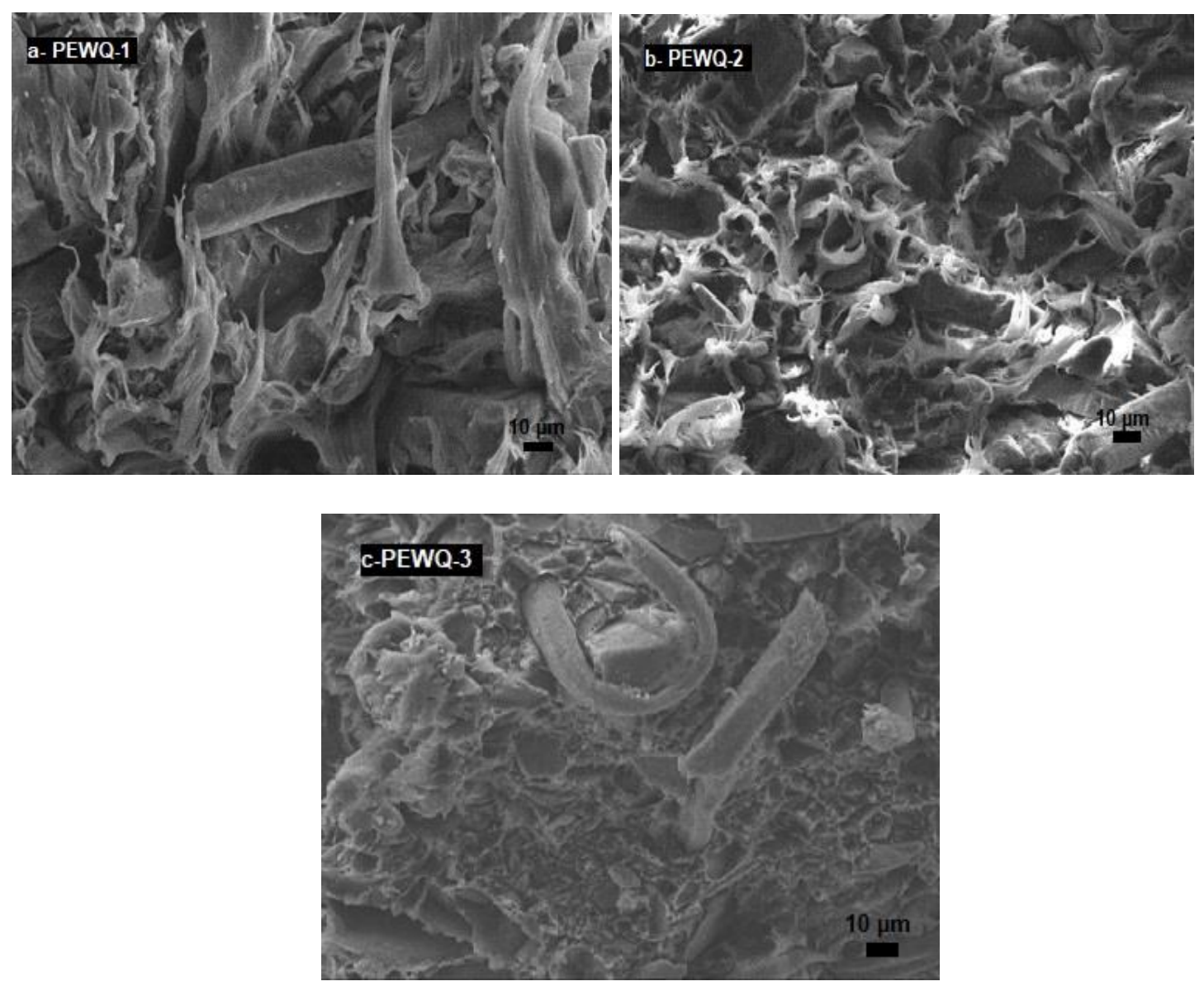

Fig. 9. SEM images of composite materials with HDPE (a), wood powder (b), and quartz substitution (c)

According to the results of the TGA obtained, HDPE samples without additives completely dissolved at approximately $480{ }^{\circ} \mathrm{C}$ and their weight was lost. In the samples containing wood dust and quartz, the degradation of the plastic material started after 300 ${ }^{\circ} \mathrm{C}$ and continued until the temperature reached 480 to $500{ }^{\circ} \mathrm{C}$. At that point the polyethylene material and wood dust had disappeared and only quartz remained. Due to the high combustion temperature of quartz, it was observed that quartz preserved its weight after $500{ }^{\circ} \mathrm{C}$ without degradation.

It was found that quartz, which is used as a mineral, retarded the degradation in the composite material and also prolonged the decomposition temperatures. According to the DSC analysis chart on HDPE, wood powder, and quartz added samples, the reaction beginning temperature of the test samples started around 25 to $30{ }^{\circ} \mathrm{C}$. The peak point of HDPE was at a heat flow rate of $29 \mathrm{~m} / \mathrm{W}$ compared to the doped ones, while it was at a heat flow rate of 18 to $19 \mathrm{~m} / \mathrm{W}$ in the groups with wood dust and quartz additives. Melting temperature was observed in the range of 125 to $135^{\circ} \mathrm{C}$ in all groups. In the SEM Images, the wood powder and quartz added into the test samples showed homogeneous distribution in the polymeric composite element. It was clearly apparent that the components entering the mixture were compatible with the segments inside and the bonding between them.

In this study, the usability of quartz in plastic composite production was observed according to the results of the experiments performed on plastic HDPE, wood powder, and quartz mineral substituted test samples, and it was also seen as a result of the experiments 
in this study that quartz, wood dust, and polyethylene increased the bending strength, tensile strength, threading, and joint hardness strength. The highest strength values were achieved in composites where quartz was used more.

In all groups with thermoplastic additives, it can be said that the samples with high quartz substitution increased relatively. Moreover, according to the results of the reference samples of the HDPE material due to the technical characteristics of the plastic additive, the quartz and wood powder in the mixture worked in harmony.

\section{CONCLUSIONS}

1. When the bending test started, the samples resisted up to the maximum force, and the return of the sample to its original dimensions as a result of bending showed the plastic property of the material. No breaks or cracks were observed in the samples due to the compatibility of the components in the mixture with each other.

2. In the samples subjected to the tensile test, it was observed that there were gaps in some parts of the test sample, which was thought to be dependent on the machine speed during injection, but the tensile strength was around $20 \mathrm{~N} / \mathrm{mm}^{2}$ in the reference sample and 13 to $14.5 \mathrm{~N} / \mathrm{mm}^{2}$ in the doped samples. It was also understood that the tensile strength could be increased by paying attention to the injection machine speed setting to prevent gaps.

3. In the screw pull resistance test and Janka hardness resistance test results, it was observed that there was an increase in the threading resistance and Janka hardness resistance of the samples. It can be mentioned that this was due to the technical properties of HDPE and quartz. The hardness of quartz showed its effect in the experiments. As the quartz amount increased, threading and Janka hardness values increased. The adherence of the components that make up the composite material was positive in terms of mechanical properties.

4. According to the results of the TGA obtained, HDPE samples without additives completely decomposed at approximately $480{ }^{\circ} \mathrm{C}$ and lost their weight. It was seen that in the samples containing wood dust and quartz, the degradation of the plastic material started after $300{ }^{\circ} \mathrm{C}$ and continued until the temperature reached 480 to 500 ${ }^{\circ} \mathrm{C}$. At that point the polyethylene material and wood dust had disappeared, and only quartz remained. Due to the high combustion temperature of quartz, it was observed that quartz preserved its weight after $500{ }^{\circ} \mathrm{C}$ without degradation. It was found that quartz, which is used as a mineral, retarded the degradation in the composite material and also prolonged the decomposition temperatures.

5. According to the DSC analysis chart on HDPE, wood powder, and quartz added samples, the reaction beginning temperature of the test samples started around 25 to $30{ }^{\circ} \mathrm{C}$. The peak point of HDPE was at a heat flow rate of $29 \mathrm{~m} / \mathrm{W}$ compared to the doped ones, while it was at a heat flow rate of 18 to $19 \mathrm{~m} / \mathrm{W}$ in the groups with wood dust and quartz additives. Melting temperature was observed in the range of 125 to $135^{\circ} \mathrm{C}$ in all groups.

6. In the SEM images, the wood powder and quartz added into the test samples showed homogeneous distribution in the polymeric composite element. It was clearly apparent

Yıldırım \& Furkan Yıldırım (2021). "Wood-Qz composite,” BioResources 16(2), 3607-3622. 3619 
that the components entering the mixture were compatible with the segments inside and the bonding between them.

7. In all groups with thermoplastic additives, the samples with high quartz substitution increased relatively. In addition, according to the results of the reference samples of the HDPE material due to the technical characteristics of the plastic additive, the quartz and wood powder in the mixture worked in harmony.

\section{ACKNOWLEDGEMENTS}

The authors are grateful for the support of the Research Fund of the Aydin Adnan Menderes University. This research was supported by Research Fund of the Aydin Adnan Menderes University, Project Number; AYMYO-19001.

\section{REFERENCES CITED}

Altuntaş, E., Salan, T., and Alma, H. M. (2016). "Investigation of fire resistance of MDFLDPE wood plastic composites using different boron compounds," KSU Journal of Engineering Sciences 19(3), 19-23.

ASTM D618-96 (1998). "Standard practice for conditioning plastic for testing," ASTM International, West Conshohocken, PA, USA.

ASTM D638-99 (2007). "Standard test methods for tensile properties of plastics," ASTM International, West Conshohocken, PA, USA.

ASTM D790 (2007). "Standard test methods for flexural properties of unreinforced and reinforced plastics and electrical insulating materials," ASTM International, West Conshohocken, PA, USA.

ASTM D1037 (2012). "Standard test methods for evaluating properties of wood-base fiber and particle panel materials," ASTM International, West Conshohocken, PA, USA.

Bağc1, D. (2006). Nanocomposite Synthesis with Epoxy Resin, Master's Thesis, Gazi University Institute of Science, Ankara, Turkey.

Balma, A. D. (1999). Evaluation of Bolted Connections in Wood Plastic Composites, Master's Thesis, Washington State University, Pullman, WA, USA.

Bodur, M. S. (2010). The Effect of Recycling Process on Mechanical Properties of Textile Waste Reinforced Polymer Matrix Composite Materials, Master's Thesis, Istanbul Technical University, Istanbul, Turkey.

Cavdar, A. D., Mengeloglu, F., and Karakus, K. (2015). "Effect of boric acid and borax on mechanical, fire and thermal properties of wood flour filled high density polyethylene composites," Measurement 60, 6-12. DOI: 10.1016/j.measurement.2014.09.078

Chen, L. (2009). Extrudable Melamine Resin for Wood Plastic Composite, Master's Thesis, Washington State University, Pullman, PA, USA.

Crawford, D. M. (1998). The Effect of Strain on the Morphology and Mechanical Properties of Thermoplastic Polyurethane Elastomers, Ph.D. Dissertation, Virginia Commonwealth University, Richmond, VA, USA. 
Drobny, J. G. (2007). Handbook of Thermoplastic Elastomers, $1^{\text {st }}$ Edition, William Andrew Inc., Norwich, NY, USA.

DPT State Planning Organization (1996). Mining Specialization Commission Report, Industrial Raw Materials Sub-Commission (Other Industrial Minerals Working Group Report, Vol. 1), DPT, Ankara, Turkey.

Erol, M. (2007). "Lectures and course notes for MAK 4087," Mechanical Engineering Department, Dokuz Eylul University, Izmir, Turkey.

Feldman, D. (1987). Plastics Additives Handbook (2 ${ }^{\text {nd }}$ Ed.), R. Gachter, and H. Muller (eds.), Hanser Publishers, Munich, Germany. DOI: 10.1002/pol.1988.140261005

Horta, J. F., Simões, F. J., and Mateus, A. (2017). "Study of wood-plastic composites with reused high density polyethylene and wood sawdust," Procedia Manufacturing 12, 221-229. DOI: 10.1016/j.promfg.2017.08.026

İsçi, S. (2007). Synthesis and Characterization of Clay/PVA and Organoclay/PVA Nanocomposites, Ph.D. Dissertation, Istanbul Technical University, Istanbul, Turkey.

Jeong, G. (2005). Fracture Behavior of Wood-Plastic Composites (WPC), Master's Thesis, Louisiana State University and Agricultural and Mechanical College, Baton Rouge, LA, USA.

Mengeloğlu, F. (2006). "Wood-thermoplastic composites," in: $1^{\text {st }}$ Polymeric Composites Symposium and Exhibition, TMMOB Chamber of Chemical Engineers, Izmir, Turkey, pp. 471-480.

Rowel, R. M. (2006). "Advances and challenges wood polymer composites," in: Proceedings of the $8^{\text {th }}$ Pacific Rim Bio-Based Composites Symposium, Kuala Lumpur, Malaysia, pp. 2-11.

Seymour, R. W., and Cooper, S. L. (1971). "DSC studies of polyurethane block polymers," Journal of Polymer Science Part B: Polymer Letters 9(9), 689-694. DOI: 10.1002/pol.1971.110090911

Seymour, R. W., and Cooper, S. L. (1973). "Thermal analysis of polyurethane block polymers," Macromolecules 6(1), 48-53. DOI: 10.1021/ma60031a008

Seymour, R. W., and Cooper, S. L. (1974). "Viscoelastic properties of polyurethane block polymers," Rubber Chemistry and Technology 47(1), 19-31. DOI: $10.5254 / 1.3540425$

Seymour, R. W., Overton, J. R., and Corley, L. S. (1975). "Morphological characterization of polyester-based elastoplastics," Macromolecules 8(3), 331-335. DOI: $10.1021 / \mathrm{ma} 60045 \mathrm{a} 017$

Sormana, J. L. (2005). Combinatorial Synthesis and High-throughput Characterization of Polyurethaneureas and Their Nanocomposites with Laponite, Ph.D. Dissertation, Georgia Tech, Atlanta, GA, USA.

Swoboda, B., Buonomo, S., Leroy1, E., and Lopez Cuesta, J. M. (2008). "Fire retardant poly(ethylene terephthalate)/polycarbonate/triphenyl phosphite blends," Polymer Degradation and Stability 93(5), 910-917. DOI:

10.1016/j.polymdegradstab.2008.02.003

Şahmetlioğlu, E., Toppare, L., and Demir, İ. (2007). Synthesis and Characterization of Metal-Contained Conductive Polymers (Tubitak Project Final Report, Project No: 104M406), Niğde, Turkey.

Tavman, D. H., and Turgut, A. (2006). "Mechanical properties of micro and nano-sized particle-added polymer composites," in: Proceedings of $11^{\text {th }}$ International Materials Symposium, Denizli, Turkey, pp. 570-575. 
TS EN 323 (1999). "Wood based boards-determination of unit volume weight," Turkish Standards Institution, Ankara, Turkey.

TS EN 326 (1999). "Sampling of wood-based boards and preparation of test pieces," Turkish Standards Institution, Ankara, Turkey.

Yildırım, K. (2020). "Investigation of wood-plastic-quartz substituted composite material characteristics," Emerging Materials Research 9(4), 1-6. DOI: 10.1680/jemmr.20.00134

Y1lmaz Bayhan, A. (2006). Synthesis and Characterization of Maleic Anhydride Grafted Oligomers and i-pp / Silicate Nanocomposites by Reactive Extrusion Method, Master's Thesis, Hacettepe University, Ankara, Turkey.

Zielinski, R., and Rutkowska, M. (1986). "A dielectric study of the glass transition region in urethane elastomers modified by ionic bonds," Journal of Applied Polymer Science 31(4), 1111-1118. DOI: 10.1002/app.1986.070310413

Article submitted: October 31, 2020; Peer review completed: February 13, 2021; Revised version received and accepted: February 14, 2021; Published: March 31, 2021.

DOI: 10.15376/biores.16.2.3607-3622 